\title{
Activity-Dependent Anchoring of Importin $\alpha$ at the Synapse Involves Regulated Binding to the Cytoplasmic Tail of the NR1-1a Subunit of the NMDA Receptor
}

\author{
Rachel A. Jeffrey, ${ }^{1}$ Toh Hean Ch'ng, ${ }^{2}$ Thomas J. 0’Dell, ${ }^{3}$ and Kelsey C. Martin ${ }^{1,2,4}$ \\ Departments of ${ }^{1}$ Biological Chemistry, ${ }^{2}$ Psychiatry and Biobehavioral Sciences, and ${ }^{3}$ Physiology and ${ }^{4}$ Semel Institute for Neuroscience and \\ Human Behavior, David Geffen School of Medicine, University of California, Los Angeles, Los Angeles, California 90095-1737
}

\begin{abstract}
Synaptic plasticity, the capacity of neurons to change the strength of their connections with experience, provides a mechanism for learning and memory in the brain. Long-term plasticity requires new transcription, indicating that synaptically generated signals must be transported to the nucleus. Previous studies have described a role for importin nuclear transport adaptors in mediating the retrograde transport of signals from synapse to nucleus during plasticity. Here, we investigated the possibility that stimulus-induced translocation of importins from synapse to nucleus involves activity-dependent anchoring of importins at the synapse. We show that importin $\alpha$ binds to a nuclear localization signal (NLS) present in the cytoplasmic tail of NR1-1a. This interaction is disrupted by activation of NMDA receptors in cultured neurons and by stimuli that trigger late-phase, but not early-phase, long-term potentiation of CA3-CA1 synapses in acute hippocampal slices. In vitro PKC phosphorylation of GST-NR1-1a abolishes its ability to bind importin $\alpha$ in brain lysates, and the interaction of importin $\alpha$ and NR1 in neurons is modulated by PKC activity. Together, our results indicate that importin $\alpha$ is tethered at the postsynaptic density by binding to the NLS present in NR1-1a. This interaction is activity dependent, with importin $\alpha$ being released following NMDA receptor activation and phosphorylation rendering it available to bind soluble cargoes and transport them to the nucleus during transcription-dependent forms of neuronal plasticity.
\end{abstract}

\section{Introduction}

We, and others, have previously shown that the classical nuclear import pathway provides one manner by which synaptically generated signals can reach the nucleus (Thompson et al., 2004; Otis et al., 2006; Dieterich et al., 2008; Lai et al., 2008; Jordan and Kreutz, 2009; Perry and Fainzilber, 2009). Proteins bearing a nuclear localization signal (NLS) are recognized by a nuclear transport adaptor protein, importin $\alpha$, which forms a heterotrimeric complex with the nuclear transporter importin $\beta 1$ (Goldfarb et al., 2004). This complex docks at the nuclear pore and undergoes facilitated transport into the nucleus. We found that importin $\alpha 1$ and $\alpha 2$ were present in postsynaptic density (PSD) fractions of mouse brain and that activation of NMDA receptors triggered translocation of importins $\alpha$ and $\beta 1$ into the nucleus of cultured hippocampal neurons. In Aplysia sensory neurons, inhibition of importin-mediated transport blocked long-term facilitation without affecting basal synaptic transmission or short-term facilitation (Thompson et al., 2004). Collectively, these data indicate

Received July 10, 2009; revised 0ct. 5, 2009; accepted 0ct. 24, 2009.

This work was supported by National Institutes of Health (NIH) Grant R01MH077022 (to K.C.M.), R01MH609197 (to T.J.O.), NIH Training Grant T32GM007185 (to R.A.J.), and a University of California Dissertation Year Award (to R.A.J.). We thank K. Olofsdotter Otis for initial comparison of PSD and NLS databases, J. Boulter for full-length GFP-NR1-1a and -2a cDNAs, M. Honsberger and M. Mason for advice on statistical analyses, and D. Black, F. Schweizer, L. Zipursky, and members of the Martin laboratory for helpful discussions.

Correspondence should be addressed to Kelsey C. Martin, 615 Charles E. Young Drive South, 390-B BSRB, Los Angeles, CA 90095-1737. E-mail: kcmartin@mednet.ucla.edu.

D01:10.1523/JNEUROSCI.3314-09.2009

Copyright $\odot 2009$ Society for Neuroscience ～0270-6474/09/2915613-08\$15.00/0 that importin-mediated signaling is required for long-term synaptic plasticity.

How do importins localize to the synapse to be available to transport stimulus-activated cargoes? Here, we explored the possibility that synaptic localization is mediated by importin binding to a resident PSD protein. Toward this end, we compared a proteomic PSD database (http://www.genes2cognition.org/cgi-bin/ GeneListView?stable_id=L00000008) (Husi and Grant, 2001) with a database of putative NLSs (http://cubic.bioc.columbia. edu/predictNLS/) (Cokol et al., 2000) and identified 28 NLScontaining PSD proteins (supplemental Table S1, available at www.jneurosci.org as supplemental material). Of these, NR1-1a, a splice variant of the NMDA receptor NR1 subunit, was particularly interesting given our earlier finding that importin translocation to the nucleus was triggered by NMDA receptor activation (Thompson et al., 2004). Of further interest, the NR1-1a splice variant of NR1 has been shown to be specifically required for efficient transcriptional responses to NMDA receptor activation (Bradley et al., 2006). Finally, the NLS in NR1-1a is known to be functional, as it can direct the nuclear import of a normally cytosolically restricted protein (Holmes et al., 2002). Together, these findings suggested that importin $\alpha$ binding to the NLS in NR1-1a might serve to localize importins to the PSD.

The NLS in NR1-1a is flanked by three protein kinase C (PKC) phosphorylation sites and one cAMP-activated protein kinase (PKA) phosphorylation site (Tingley et al., 1997). Phosphorylation of residues flanking NLSs can change the affinity of importin for its cargo proteins (Poon and Jans, 
2005). Phosphorylation could thus modulate the binding of importin $\alpha$ to NR1, thereby regulating the anchoring of importins at synapses.

In the present study we show that importin $\alpha$ binds specifically to a NLS present in the cytoplasmic tail of the NR1-1a subunit of the NMDA receptor. This interaction is regulated by activity; binding is significantly reduced by stimuli known to produce long-lasting synaptic plasticity. Phosphorylation of residues within and flanking the NLS in NR1 interferes with the binding of importin $\alpha$ to NR1. Together, our findings indicate that importin $\alpha$ is anchored at synapses by binding to the NLS in NR1-1a, and that this binding is regulated in an activity- and phosphorylation-dependent manner during transcription-dependent plasticity.

\section{Materials and Methods}

Antibodies. Antibodies used include the following: rabbit anti-importin $\alpha 1$ and importin $\alpha 2$, gifts from Marian Waterman (University of California, Irvine, Irvine, CA); rabbit anti-Rch1, Bethyl Laboratories; custom-made rabbit polyclonal anti-isoform-specific importin $\alpha$ (described in supplemental material, available at www.jneurosci.org); rabbit anti-synaptophysin and anti-MAP2, Millipore Bioscience Research Reagents; mouse antiMAP2, Sigma (clone HM-2); mouse anti-NR1 C terminus, Millipore, rabbit anti-NMDAR1 C1 cassette, AbCam; rabbit anti-NR1 pSer896 (Calbiochem); rabbit anti-NR1 pSer890, pSer896, and pSer897, Cell Signaling Technology; mouse anti-FLAG, Sigma; mouse anti-calmodulin, Millipore; mouse antiPSD-93 (Chapsyn-110), NeuroMab; and mouse anti-GAPDH, AbCam.

Rat hippocampal and cortical cultures. Primary neuronal cultures from postnatal day 0 (P0) Sprague Dawley rats grown in defined media were prepared as previously described (Lai et al., 2008); detailed protocol is available at http://www.biolchem.ucla.edu/labs/martinlab/. For glutamate stimulation, neurons [ $21 \mathrm{~d}$ in vitro (DIV)] were silenced for $6 \mathrm{~h}$ with $1 \mu \mathrm{M}$ tetrodotoxin (TTX) and then stimulated by replacing the media with media containing $40 \mu \mathrm{M}$ glutamate $+1 \mu \mathrm{M}$ TTX for $5 \mathrm{~min}$. For PKC manipulation, neurons (21 DIV) were silenced for $6 \mathrm{~h}$ with $1 \mu \mathrm{M}$ TTX and then incubated with $20 \mathrm{nM}$ PMA for activation or preincubated for 30 min with $5 \mu \mathrm{M}$ chelerythrine for inhibition or vehicle in $37^{\circ} \mathrm{C}$ incubator for $5 \mathrm{~min}$ before fixation. For PKA manipulations, after silencing as above, neurons were activated with $25 \mu \mathrm{m}$ forskolin or inhibited with 60 $\mu \mathrm{M}$ KT5720 for 30 min before glutamate. For biochemistry, after $6 \mathrm{~h}$ silencing with $1 \mu \mathrm{M}$ TTX, PKA or PKC was activated with $25 \mu \mathrm{M}$ forskolin or 20 nM PMA for 10 min and then lysed in 1\% Triton X HNTG.

PSDs and synaptosomes. Synaptosomes and PSD fractions were prepared from P21-P28 Sprague Dawley rats as described at http://www. biolchem.ucla.edu/labs/martinlab/.

Hippocampal slice preparation and electrophysiology. CA1 "mini-slices" from 8- to 10-week-old male C57BL/6 mice were used as previously described (Ho et al., 2004). For experiments involving APV, $100 \mu \mathrm{M}$ D-APV was bath applied for $30 \mathrm{~min}$ before stimulation. High-frequency stimulation (HFS) consisted of either one or two trains of $100 \mathrm{~Hz}$ stimulation ( $1 \mathrm{~s}$ in duration) with an intertrain interval of $10 \mathrm{~s}$. A single pulse of presynaptic fiber stimulation was delivered $5 \mathrm{~s}$ after HFS to ensure that HFS induced a twofold or greater increase in population spike amplitude.

Immunostaining. Cultures were processed as previously described (Thompson et al., 2004) except that $0.5 \%$ Triton X-100 was used.

Immunoblots. Proteins were resolved by $10 \%$ SDS-PAGE, transferred to a polyvinylidene fluoride membrane, blocked in TBS-T 5\% milk or $5 \%$ BSA with phosphatase inhibitors, and probed with primary antibodies and HRP-conjugated secondary antibodies and detected by chemiphospholuminescence.

Image acquisition and analysis. Images were obtained using a Zeiss Pascal scanning laser confocal microscope with $40 \times$ or $63 \times$ oil-immersion objectives. All images within a single experiment were acquired using equivalent settings by an individual who was blind to treatment conditions. Images were analyzed using LSM Pascal or Universal Imaging MetaMorph software. Neurons were selected at random from each quadrant of the coverslip by MAP2 staining. Nuclei were manually outlined based on absence of MAP2 signal. Nuclear to cytoplasmic ratio was determined using Slidebook (Intelligent Imaging Innovations) software by subtracting nuclear signal from total somatic signal. Colocalization of NR1 and importin $\alpha$ was determined using Slidebook software. Colocalization in NR1-containing puncta was determined using Slidebook by thresholding all NR1 signal to include true synaptic puncta in size and brightness. Importin $\alpha$ signal was then collected from these puncta after thresholding above background. Signal intensity of immunoblots were measured with ImageQuant software (General Electric) and normalized to control bands.

Statistics. All statistical analysis was done using SPSS software.

Plasmids. GST was fused to the N terminus of NR1-1a and NR1-2a cytoplasmic tails in pGEX vector (GE Healthcare). FLAG-importin $\alpha 1$ was previously described (Lai et al., 2008).

Immunoprecipitation. Rat forebrains were homogenized in HNTG lysis buffer (50 mM HEPES, pH 7.3, $150 \mathrm{~mm} \mathrm{NaCl}, 1.5 \mathrm{~mm} \mathrm{MgCl}_{2}, 10 \%$ glycerol, $1 \mathrm{~mm}$ EDTA, and $1 \%$ Triton-X, $100 \mathrm{pH}$ 7.5) containing protease inhibitor cocktail (Roche), $\mathrm{NaF}$ (10 mM), and Na-orthovanadate (1 mM), spun at low speed $(1000 \times g)$ for $10 \mathrm{~min}$ and high speed $(10,000 \times g)$ for $10 \mathrm{~min}$. Lysates were precleared with protein A (for rabbit antibodies) or protein $\mathrm{G}$ (GE Healthcare, for mouse antibodies) for $2 \mathrm{~h}$ at $4^{\circ} \mathrm{C}$ and incubated with $10 \mu \mathrm{g} / \mathrm{ml}$ concentration of antibodies and $25 \mu \mathrm{l}$ of a $50 \%$ slurry of either protein A or protein $\mathrm{G}$ beads at $4^{\circ} \mathrm{C}$ overnight. Immunoprecipitates were washed with lysis buffer and eluted by boiling in Laemmli buffer. Protein concentration determined by Bradford assay (Bio-Rad).

GST pull-down assays. GST pull-downs in transfected HEK cells and brain lysates were performed as previously described (Lai et al., 2008) except for the use of modified RIPA as wash buffer (50 mM Tris, pH 7.9, $100 \mathrm{~mm} \mathrm{KCl}, 0.25 \% \mathrm{Na}$ deoxycholate, $0.6 \mathrm{~mm}$ EDTA, 1\% NP-40). Competition with NLS peptide was performed as previously described (Lai et al., 2008). For in vitro phosphorylation, GST fusion proteins were incubated in kinase buffer (250 mM MES, $1 \mathrm{~mm}$ EGTA, and $10 \mathrm{~mm}$ $\mathrm{MgCl}_{2}, \mathrm{pH}$ 6.0) and $20 \mathrm{~mm}$ ATP, with or without $1 \mu \mathrm{l}(7.5 \mathrm{U})$ of recombinant active $\mathrm{PKC}_{\mathrm{M}}$ (Calbiochem), in an agitated $30^{\circ} \mathrm{C}$ water bath for $30 \mathrm{~min}$.

\section{Results \\ Importin $\alpha$ and NR1 colocalize in hippocampal spines and interact in brain lysates}

To determine whether importin $\alpha$ and NR1 colocalize at synapses, and whether colocalization is activity dependent, we performed double-label immunocytochemistry (ICC) of cultured rat hippocampal neurons (21 DIV) with anti-importin $\alpha 1$ and anti-NR1 antibodies. As shown in Figure $1 A$, importin $\alpha 1$ was present in $55 \%$ of NR1-immunoreactive dendritic spines in cultured neurons in which activity had been silenced with TTX. A brief stimulation with glutamate ( $40 \mu \mathrm{M}, 5 \mathrm{~min}$ or $15 \mathrm{~min}$ ) significantly decreased both the percentage of NR1-immunoreactive spines containing importin $\alpha 1$ and the concentration of importin $\alpha 1$ in NR1-immunoreactive spines (Fig. $1 B$ ). As we have previously reported (Thompson et al., 2004), and as shown in supplemental Figure 3 (available at www.jneurosci.org as supplemental material), $25 \mathrm{~min}$ after glutamate stimulation (40 $\mu \mathrm{M}, 5 \mathrm{~min})$, importin $\alpha 1$ accumulates in the nucleus, and is largely absent from synapses.

In complementary biochemical assays, both importin $\alpha$ and NR1 were present in synaptosome and PSD fractions prepared from adult rat forebrain (Fig. $1 C$ ). We investigated interactions between the two proteins at synapses by coimmunoprecipitation (co-IP) from synaptosomes. As shown in Figure $1 D$, importin $\alpha$ was present in NR1 immunoprecipitates, and NR1 was present in importin $\alpha$ immunoprecipitates. Neither importin $\alpha$ nor NR1 were present in parallel control immunoprecipitates with mouse anti-GFP antibodies and rabbit pre-immune serum, respectively. 
A TTX
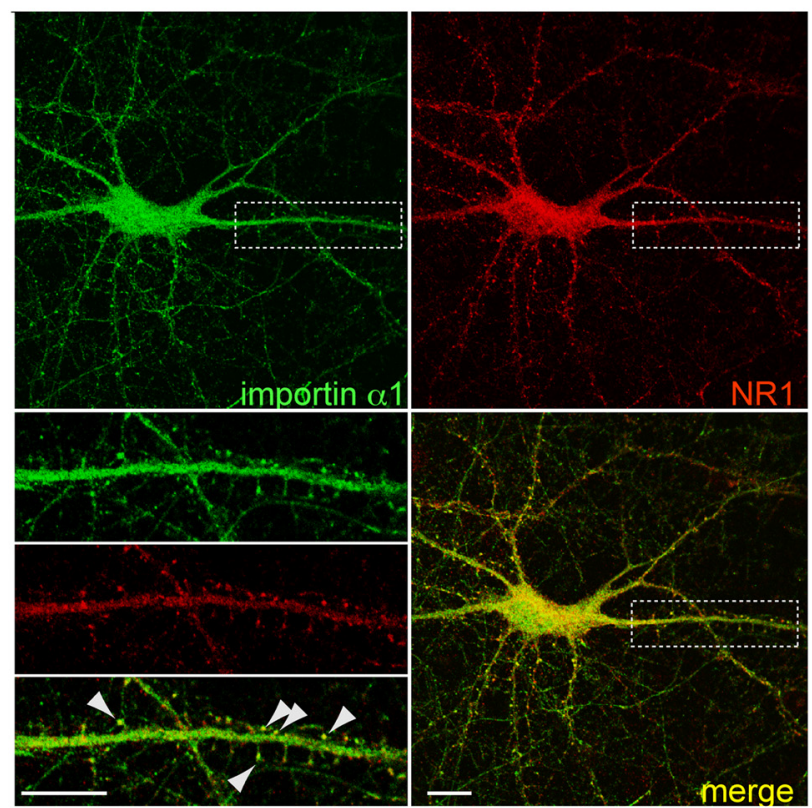

B

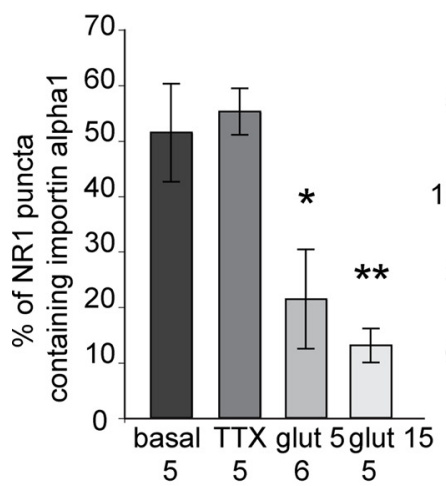

C

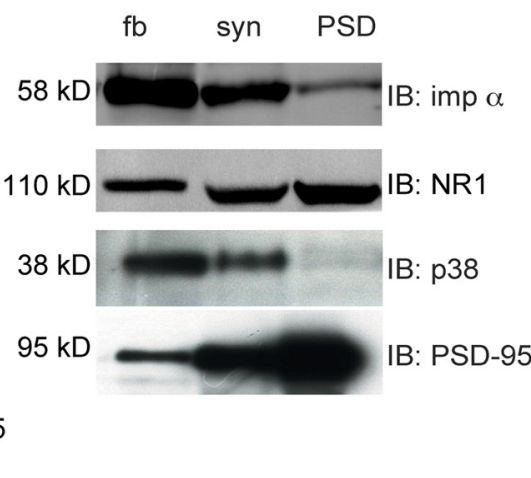

Glutamate
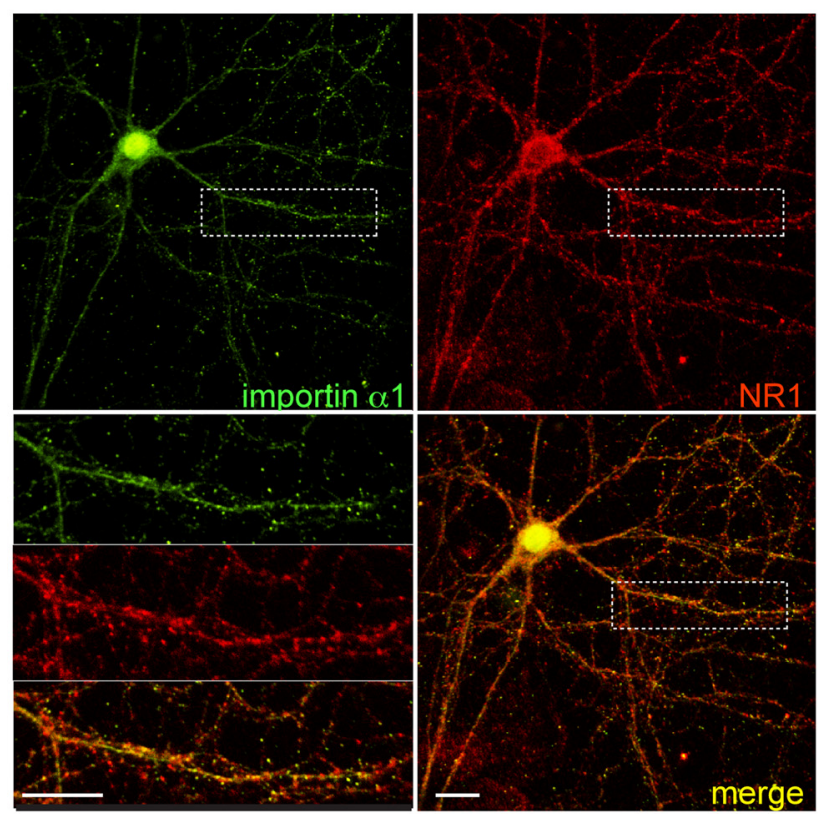

D

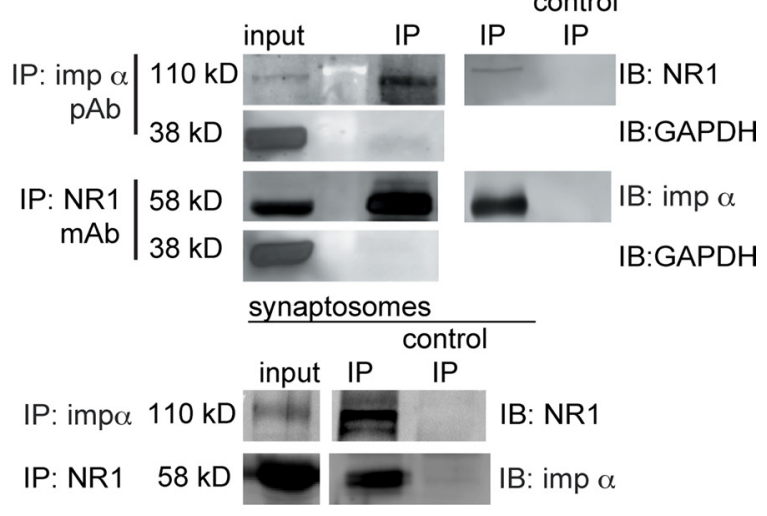

Figure 1. Interaction between NR1 and importin $\alpha$. A, Immunostaining of hippocampal neurons (21 DIV) with anti-NR1 (red) and anti-importin $\alpha$ (green) antibodies reveals partial colocalization in spines (arrowheads) of neurons silenced with TTX (1 $\mu \mathrm{M})$. Following glutamate stimulation ( $40 \mu \mathrm{M}, 15 \mathrm{~min}$ ), the concentration of importin $\alpha$ is decreased in spines and dendrites and increased in the nucleus. Scale bars, $20 \mu \mathrm{m}$. B , Quantification of the percentage of NR1-immunopositive spines containing importin $\alpha$ immunoreactivity. ${ }^{*} p<0.05$, ${ }^{* *} p<0.01$, one-way ANOVA $F_{(3,17)}=4.73, p<0.05$. Post hoc least significant difference test was performed to compare all groups $\left({ }^{*} p<0.05\right.$ ); $n$ (number of cells) for each category is given below the graph. C, IB of adult rat forebrain homogenate (fb), synaptosome (syn), and PSD fractions (equal protein concentrations) with importin $\alpha$ and NR1 antibodies shows that both proteins are present in synaptosome and PSD fractions. Synaptophysin (p38), Synaptosome marker; PSD-95, PSD marker. D, NR1 and importin $\alpha$ co-IP from adult fb and syn. IPs were performed with monoclonal anti-NR1 antibodies or with polyclonal anti-importin $\alpha$ antibodies, and immunoblots with polyclonal anti-importin $\alpha$ antibodies or with monoclonal anti-NR1 antibodies, respectively. Control immunoprecipitates included monoclonal anti-GFP antibodies (for NR1) or pre-immune rabbit serum (for importin $\alpha$ ). Anti-GAPDH antibodies were used as controls for IB. Experiments in $\boldsymbol{C}$ and $\boldsymbol{D}$ were replicated three times.

\section{Importin $\alpha$ binds NR1-1a via the NLS in the C1 cassette}

The NR1 subunit is alternatively spliced from a single gene into eight splice variants that differ in the composition of their cytoplasmic tails (Hollmann et al., 1993). The NR1-1a splice variant is characterized by inclusion of exon 21, encoding the $\mathrm{C} 1$ cassette, which contains the NLS. To determine whether importin $\alpha$ specifically binds the NLS in NR1-1a, we generated GST fusion proteins of the cytoplasmic tail of NR1-1a and NR1-2a, which are identical except that NR1-1a contains the NLS-containing C1 cassette and NR1-2a does not (Fig. 2A). GST-pull-down experiments in rat forebrain lysates revealed that GST-NR1-1a, but neither NR1-2a nor GST alone bound importin $\alpha$ (Fig. $2 C)$. In control experiments, both GST-NR1 fusion constructs bound calmodulin (supplemental Fig. S1 A, available at www. jneurosci.org as supplemental material), consistent with pub- lished results (Ehlers et al., 1996). In a complementary set of experiments, we found that GST-NR1-1a pulled down FLAGtagged importin $\alpha$ heterologously expressed in HEK 293-T cells (supplemental Fig. S1B, available at www.jneurosci.org as supplemental material).

To confirm that importin binds the NLS in NR1-1a, we conducted competition experiments with peptides containing the NLS of $N F \kappa B$ (VQRKRQKLM), which has been shown to bind importin $\alpha$ and block nuclear translocation of importin $\alpha$ cargoes (Torgerson et al., 1998; Lai et al., 2008). A mutant peptide (mNLS) with two amino acid changes in the NLS (VQRNGQKLMP) does not bind importin $\alpha$ and served as a negative control. Preincubation of lysates with the NLS peptide effectively interfered with importin binding to NR1, whereas mNLS peptides did not (Fig. 2D), providing evidence that importin $\alpha$ binds NR1-1a through its NLS binding sites. 
A

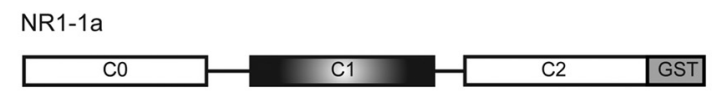

NR1-2a
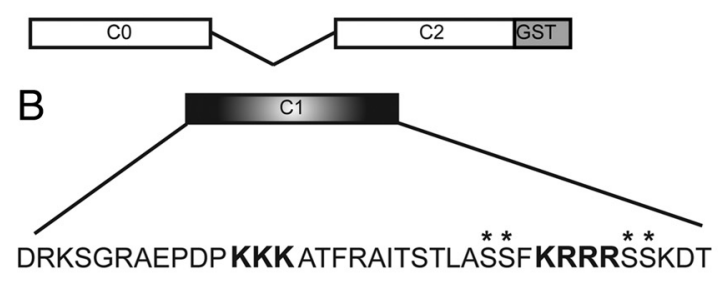

C
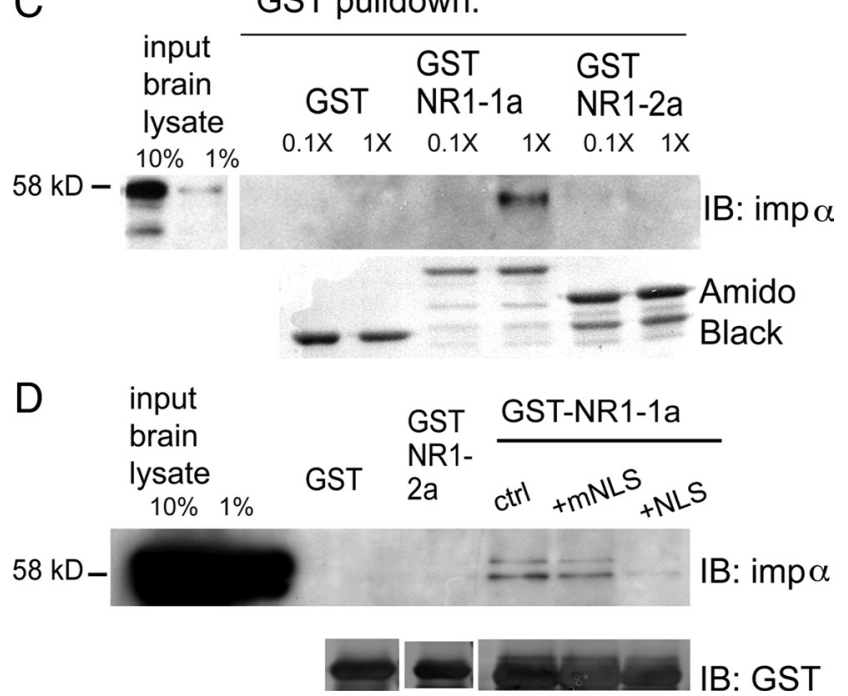

Figure 2. NR1-1a binds importin $\alpha$ via its NLS. $\boldsymbol{A}$, The cytoplasmic tails of NR1-1a and NR1-2a were fused to GST. $\boldsymbol{B}$, Amino acid sequence of the C 1 cassette, with the NLS in bold; asterisks denote phosphorylation sites. C, Importin $\alpha$ binds GST NR1-1a but not NR1-2a or GST alone in adult rat forebrain lysates. Two input lanes show $10 \%$ and $1 \%$ of input used for pull-downs. The concentration of input lysate was $0.1 \times$ or $1 \times(2.3 \mathrm{mg})$, as indicated. Amido black shows amount of GST fusion proteins, which have distinct molecular weights. $\boldsymbol{D}$, The interaction between importin $\alpha$ and GST-NR1-1a is inhibited by preincubation with 100 -fold molar excess NLS but not mutant NLS (mNLS) peptide. Ctrl, No-peptide control. The presence of two bands is due to the fact that the importin $\alpha$ antibody recognizes importin $\alpha 1$ [molecular weight (MW) $61 \mathrm{kDa}$ ] as well as importin $\alpha 2$ (MW $58 \mathrm{kDa}$ ).

The interaction between importin $\alpha$ and NR1 is activity dependent

To determine whether the interaction between importin $\alpha$ and NR1 is regulated by activity, we monitored importin $\alpha$-NR1 interactions in primary cultured cortical neurons following stimuli known to trigger nuclear translocation of importins (Thompson et al., 2004). Cortical cultures (21 DIV) were silenced with TTX ( $1 \mu \mathrm{M}, 6 \mathrm{~h})$, incubated with $40 \mu \mathrm{M}$ glutamate (or vehicle) for $5 \mathrm{~min}$, lysed, and processed for co-IP with NR1 or importin $\alpha$ antibodies. In TTX-silenced neurons, importin $\alpha$ was present in NR1 immunoprecipitates (Fig. 3A), and NR1 was present in importin $\alpha$ immunoprecipitates (supplemental Fig. S5, available at www.jneurosci.org as supplemental material). This interaction was significantly decreased following glutamatergic stimulation. Glutamate did not alter the total concentration of either importin $\alpha$ or NR1 (Fig. $3 A$, input lanes).

We next asked whether stimuli that elicit long-lasting, transcription-dependent forms of hippocampal plasticity altered
A Glutamate stimulation

input

cultures

IP: NR1

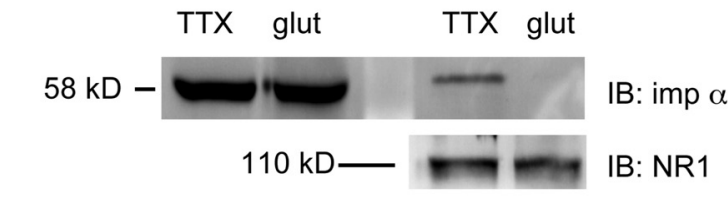

B $1 \times 100 \mathrm{~Hz}$

input

$\frac{\text { hipp. slices }}{\text { ctrl } 1 \times 100} \frac{\text { IP: NR1 }}{\text { US } 1 \times 100}$

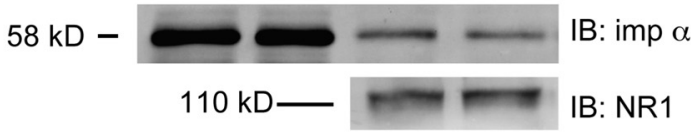

$2 \times 100 \mathrm{~Hz}$

input IP: IP:

$\frac{\text { hipp. slices }}{\text { ctrl } 2 \times 100} \quad \frac{\text { NR1 }}{\text { US } 2 \times 100}$ GFP

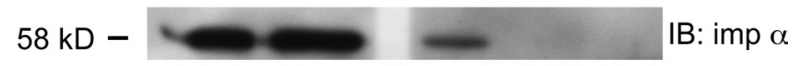

$110 \mathrm{kD} \longrightarrow$ IB: NR1

93 kD $-\mathrm{IB}: \mathrm{PSD}-93$

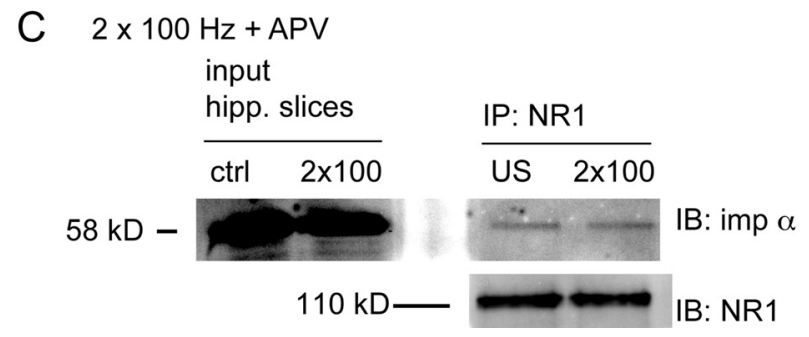

Figure 3. NR1-importin $\alpha$ binding is regulated by activity. A, 21 DIV cortical neurons were silenced with TTX $(1 \mu \mathrm{m})$ for $6 \mathrm{~h}$, incubated with $40 \mu \mathrm{m}$ glutamate or vehicle for 5 min, lysed, and processed for IP with anti-NR1 antibodies, followed by IB for importin $\alpha$ (or NR1 as control). Importin $\alpha$ binds NR1 in TTX silenced neurons; binding is reduced following glutamate stimulation [TTX alone $=392.47 \pm 67.58$ arbitrary units (а.u.); glut $=92.07 \pm 45.09$ a.u., $p<0.002$, independent-samples $t$ test; $n$ ( $n$ always represents number of independent experiments) $=3$ ]. $\boldsymbol{B}$, Hippocampal CA1 minislices were stimulated one or two times at $100 \mathrm{~Hz}(1 \times 100,2 \times 100)$, lysed, and processed for IP with anti-NR1 antibodies followed by IB for importin $\alpha$. Unstimulated (US) slices from the same chamber served as controls. Importin $\alpha$ is present in equal concentrations in NR1 immunoprecipitates from US slices and slices receiving $1 \times 100 \mathrm{~Hz}$ stimuli, but is reduced following stimulation with $2 \times 100 \mathrm{~Hz}$ tetani (US $=1.00 \pm 0.07$ a.u.; $1 \times 100 \mathrm{~Hz}=$ $1.08 \pm 0.05$ a.u.; $2 \times 100 \mathrm{~Hz}=0.42 \pm 0.17$ a.u.; $1 \times 100 \mathrm{~Hz}$ vs US $p>0.05, \mathrm{~ns} ; 2 \times 100$ $\mathrm{Hz}$ vs US $p<0.04$, independent-samples $t$ test; $n=4$ ). IB with NR1 antibodies reveals equal NR1 concentrations in stimulated and US slices. Additional controls include IP with GFP antibodies and IB with PSD-93 antibodies. C, The reduction in importin $\alpha$ binding to NR1 is blocked by preincubation with the NMDA receptor antagonist APV (100 $\mu \mathrm{M}$ ) (APV alone $=2.14 \pm 0.19$ a.u.; APV $+2 \times 100 \mathrm{~Hz}=2.00 \pm 0.21$ a.u.; $p>0.05$, ns, independent-samples $t$ test; $n=4$ ).

binding of importin $\alpha$ to NR1. Experiments were performed in CA1 minislices (Nayak et al., 1996) using a large bipolar stimulating electrode that spanned the full extent of stratum radiatum to activate Schaffer collateral fiber inputs onto CA1 pyramidal cells. Presynaptic fibers were stimulated with a single train of HFS $(100 \mathrm{~Hz}$ for $1 \mathrm{~s})$ to induce early long-term potentiation (LTP) or 
with two trains of HFS (intertrain interval $=10 \mathrm{~s}$ ), a protocol that induces protein synthesis-dependent late-phase LTP (Osten et al., 1996) as well as transcription-dependent potentiation ( $R$. Blitzer, personal communication). These lysates were used for co-IP experiments. As shown in Figure 3B, NR1 antibodies coim-

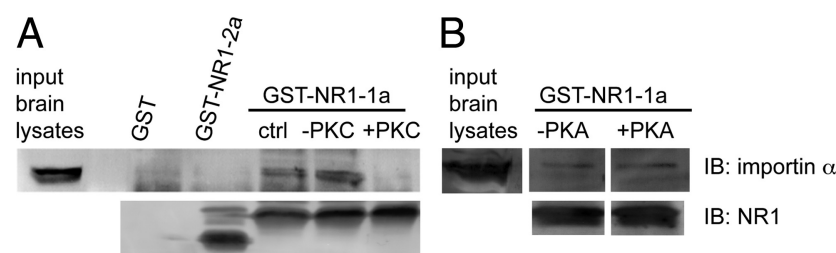

Figure 4. PKC phosphorylation of NR1 disrupts importin $\alpha$ binding. A, GST-NR1 C-terminal constructs were phosphorylated in vitro with recombinant PKC (-PKC, GSTNR1-1a incubated with ATP but without PKC). Unphosphorylated GST-NR1-1a (ctrl and -PKC) pulls down importin $\alpha$; this interaction is abrogated by PKC phosphorylation of GST-NR1-1a ( + PKC $=0.378 \pm 0.131$ a.u.; - PKC $=0.940 \pm 0.133$ a.u.; $p<0.006$ independent $t$ test; $n=4)$ ). IB with NR1 antibodies shows equal concentration of GST-NR1 constructs in each condition (GST-NR1-2a smaller due to lack of (1 cassette). B, GSTNR1-1a constructs were phosphorylated in vitro with recombinant PKA (-PKA, GSTNR1-1a incubated with ATP but without PKA). Both unphosphorylated GST-NR1-1a (-PKA) and PKA phosphorylated GST-NR1-1a pull-down importin ( + PKA $=1.33 \pm$ 0.03 a.u.; - PKA $=1.43 \pm 0.04$ a.u.; $p>0.05$, ns, independent $t$ test; $n=3$ ). IB with NR1 antibodies shows equal concentration of GST-NR1 constructs in each condition.
A
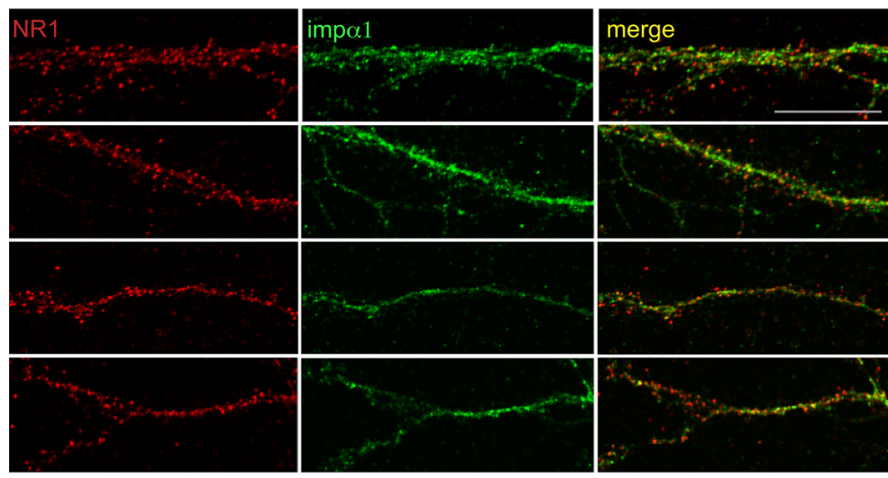

Basal

TTX

Glut

Glut

+ chel
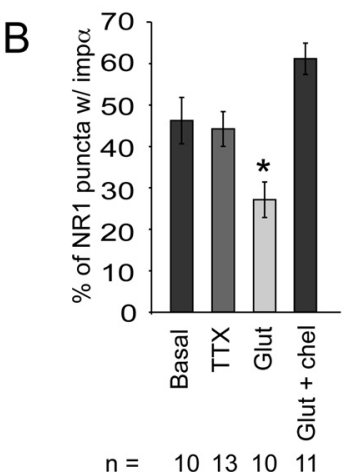

C

input

cortical

cultures IP: NR1

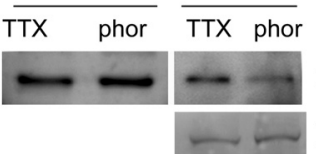

IB: impa

IB: NR1

$n=1013 \quad 10 \quad 11$
Figure 5. PKC is necessary for importin $\alpha$ dissociation from NR1 with glutamate stimulation. $\boldsymbol{A}$, Immunostaining of hippocampal neurons (21 DIV) with anti-NR1 (red) and anti-importin $\alpha$ (green) antibodies reveals partial colocalization in spines of neurons silenced with $\operatorname{TTX}(1 \mu \mathrm{M})$, with decreased colocalization after glutamate stimulation ("glut," $40 \mu \mathrm{m}, 8 \mathrm{~min})$. When preincubated for 30 min with specific inhibitors of PKC ("glut + chel", $5 \mu \mathrm{m}$ chelerythrine), glutamate does not decrease the colocalization of importin $\alpha$ and NR1. $B$, Quantification of the percentage of NR1-immunopositive spines containing importin $\alpha$ immunoreactivity (one-way ANOVA $\left.F_{(7,84)}=5.66, p<0.001\right)$. Post hoc Dunnett's test was performed to compare all groups to glutamate $\left(^{*} p<\right.$ $0.05 ; n$, number of cells). Scale bars, $20 \mu \mathrm{m}$. C, TTX-silenced cortical neurons (21 DIV) were incubated with 20 nm phorbol esters (phor) to activate PKC or vehicle (TTX, $1 \mu \mathrm{m}$ ) for $10 \mathrm{~min}$, lysed, and processed for IP with anti-NR1 antibodies followed by IB with anti-importin $\alpha$ antibodies. More importin $\alpha$ is present in NR1 immunoprecipitates from control cultures (TTX) than in cultures in which PKC is activated by phorbol esters (phorbol esters $=83 \pm 4.7 \%$ of TTX control; $p<0.05$, 1-sample $t$ test; $n=4$ ). NR1 IB reveals equal concentration of NR1 in all conditions. munoprecipitated importin $\alpha$ in unstimulated slices and in slices ced disruption of importin $\alpha$-NR1 binding required NMDA PV (Fig. 3C).

Together, these experiments indicate that the binding of mportin $\alpha$ to NR1 is regulated by activity. Binding occurs in synapses and is maintained following stimuli neuronal plasticity. Further, the loss of binding is specifically Phosphorylation of NR1 by PKC disrupts binding of We next asked whether importin $\alpha$ binding was regulated by phosphorylation of NR1. Phosphorylation of residues flanking the NLS has been shown to either inhibit or promote binding of the NLSbearing cargo to importin $\alpha$ (Poon and Jans, 2005). The NLS in NR1-1a is flanked by three experimentally demonstrated PKC phosphorylation sites (Ser-889, Ser-890, and Ser-896) and one experimentally demonstrated PKA phosphorylation site (Ser-897) (Tingley et al., 1997). Using phosphospecific antibodies, we found that phosphorylation at Ser-890 was increased following $2 \times 100 \mathrm{~Hz}$ stimulation of acute hippocampal slices (supplemental Fig. S7, available at www. jneurosci.org as supplemental material). This finding, together with a report that PKC-mediated phosphorylation of Ser-896 is significantly increased following stimuli that elicit LTP of CA3-CA1 synapses (Moriguchi et al., 2006), further suggested that PKC and/or PKA phosphorylation of the cytoplasmic tail of NR1-1a could regulate its interaction with importin $\alpha$.

We initially focused on PKC phosphorylation by in vitro phosphorylating GST-NR1-1a with recombinant PKC and using these constructs for GST pull-down assays in brain lysates. As shown in Figure $4 A$, significantly less importin $\alpha$ bound PKC-phosphorylated GST-NR1-1a than nonphosphorylated GST-NR1-1a. We then used recombinant PKA to in vitro phosphorylate GST-NR1 constructs and conducted GST-pull-down assays in brain lysates. As shown in Figure 4B, phosphorylation of NR1 by PKA did not interfere with the binding between importin $\alpha$ and NR1. Immunoblotting (IB) with phosphospecific antibodies revealed that serines 890, 896, and 897 were phosphorylated following in vitro incubation with PKC, and that only serine 897 was phosphory- 
lated following incubation with PKA (supplemental Fig. S6 A, available at www. jneurosci.org as supplemental material). Together, these results indicate that PKC phosphorylation of serines 890 and/or 896 (and possibly serine 889 , for which phosphospecific antibodies are not available) disrupts the association of importin $\alpha$ with NR1-1a.

\section{Antagonists of PKC block glutamate-induced loss in overlap between importin $\alpha$ and NR1 in hippocampal spines}

To determine whether and how endogenous PKC activation affects the interaction between importin $\alpha$ and NR1 at synapses, we blocked PKC during glutamatergic stimulation of rat hippocampal neurons (21 DIV) and monitored synaptic localization of importin $\alpha$ by double-label ICC with anti-importin $\alpha 1$ and anti-NR1 antibodies (Fig. 5A). As shown in Figure $5 B$, importin $\alpha 1$ was present in $44 \%$ of NR1immunoreactive puncta in cultured neurons in which activity had been silenced with TTX. Consistent with data shown in Figure 1, a brief stimulation with glutamate $(40 \mu \mathrm{M}, 8 \mathrm{~min})$ significantly decreased both the percentage of NR1-immunoreactive spines containing importin $\alpha 1$ (Fig. $5 B$ ), and the concentration of importin $\alpha 1$ in NR1-immunoreactive spines (supplemental Fig. S8 $B$, available at www.jneurosci.org as supplemental material). Incubation of cultures with the specific PKC inhibitor chelerythrine (5 $\mu \mathrm{M})$ for $30 \mathrm{~min}$ before and during stimulation with glutamate blocked the decrease in importin $\alpha$ immunoreactivity in NR1containing spines, indicating that glutamate-induced loss of importin $\alpha$ from synapses requires PKC activity (Fig. $5 B$ ).

In a complementary set of experiments, we incubated dissociated rat cortical cultures (21 DIV) with TTX for $6 \mathrm{~h}$, and then applied phorbol esters ( $20 \mathrm{~nm}, 5 \mathrm{~min}$ ) to activate PKC. Cultures were lysed and used for co-IP experiments. As shown in Figure $5 C$, incubation with phorbol esters decreased the amount of importin $\alpha$ present in NR1 immunoprecipitates. Of note, no difference in binding between importin $\alpha$ and NR1 was seen following activation of PKA with forskolin $(25 \mu \mathrm{M}, 5 \mathrm{~min}$ ) (supplemental Fig. S6 $B$, available at www.jneurosci.org as supplemental material). Together with the in vitro phosphorylation data (Fig. 4A), these data support the idea that activity-dependent PKC phosphorylation of serines flanking the NLS disrupts the interaction between importin $\alpha$ and NR1.

\section{Discussion}

Long-lasting activity-dependent changes in synaptic efficacy require new transcription and thus involve the transport of signals from synapse to nucleus. While electrochemical signaling allows neurons to rapidly communicate between compartments, soluble signaling molecules have also been shown to translocate from synapse to nucleus to trigger changes in gene expression (Otis et al., 2006; Cohen and Greenberg, 2008). We, and others, have described a role for importin nuclear transporters in relaying signals from distal processes to the nucleus (Hanz et al., 2003; Thompson et al., 2004; Dieterich et al., 2008; Lai et al., 2008;
Jordan and Kreutz, 2009). In this study, we present data showing that importin $\alpha$ binds to a bipartite NLS in the NR1-1a subunit of the NMDA receptor. Our findings are consistent with this interaction serving to tether importin $\alpha$ at the PSD in an activitydependent manner. Specifically, our results suggest that NMDA receptor stimulation activates $\mathrm{PKC}$, which phosphorylates residues surrounding the NR1 NLS, decreasing the affinity of the importin-NR1 interaction and thereby releasing importin $\alpha$ so that it is available to transport soluble cargo proteins from the synapse to the nucleus. Of note, the NLS and flanking serines in the NR1 subunit are highly conserved across species (supplemental Fig. S4, available at www.jneurosci.org as supplemental material).

A precedent for stimulus-dependent anchoring of importins at the membrane through interactions with membrane proteins exists in hepatocytes, where importin $\alpha 2$ binds the Glut 2 transporter in a manner that is modulated by glucose concentrations (Guillemain et al., 2002). We also considered the possibility that the NR1-1a cytoplasmic tail was proteolytically cleaved with subsequent importin-mediated nuclear translocation of the cytoplasmic domain. In fact, another transmembrane protein present in both the PSD proteome and the putative NLS database, the L-type voltage-gated calcium channel $\mathrm{Ca}(\mathrm{V}) 1.2$, has been reported to be cleaved by calpain (De Jongh et al., 1994) and to translocate to the nucleus (Gomez-Ospina et al., 2006). Our finding that activity decreases the interaction between NR1 and importin $\alpha$ (Fig. 3) argues against cleavage of NR1 and subsequent importin-mediated nuclear transport. Two additional experiments indicate that NR1 does not undergo activity-dependent cleavage. First, we immunoblotted lysates of hippocampal slices with NR1 antibodies and did not detect smaller products or decreases in full-length NR1 following $2 \times 100 \mathrm{~Hz}$ stimulation (supplemental Fig. S2 A, available at www.jneurosci.org as supplemental material). Second, ICC of cultured hippocampal neurons with antibodies directed against the $\mathrm{C} 1$ or $\mathrm{C} 0$ cassette of NR1 
did not reveal any nuclear immunoreactivity in the presence or absence of glutamate stimulation (supplemental Fig. S2 B, available at www.jneurosci.org as supplemental material). This is consistent with an earlier report that full-length NR1 with a C-terminal GFP tag expressed in neurons localized to the cytosol and plasma membrane, with no nuclear GFP signal (Marsh et al., 2001).

The NMDA receptor plays a critical role in learning-related synaptic plasticity (Malenka and Bear, 2004), and as such is an ideal candidate anchor for importin $\alpha$. The NR1 subunit undergoes alternative splicing to generate receptors with distinct cytoplasmic tails, which endow the receptor with distinct properties (Durand et al., 1992, 1993; Sugihara et al., 1992) (for review, see Zukin and Bennett, 1995). NR1 splicing is regulated developmentally (Monyer et al., 1994; Sheng et al., 1994) and by activity (Mu et al., 2003). Alternative NR1 splicing has been shown to regulate membrane expression of the receptor (Pérez-Otaño and Ehlers, 2005). Thus, the C0 cassette has been reported to mediate endocytosis and degradation (Scott et al., 2004) and sequences in the $\mathrm{C} 1$ cassette, contained within the NLS, have been reported to function as endoplasmic reticulum (ER) retention signals (Scott et al., 2001; Xia et al., 2001). NR1 ER retention is regulated by phosphorylation of residues flanking the ER retention signal and by sequences within the $\mathrm{C} 2$ cassette, leading to changes in the way that the NMDA receptor is trafficked and targeted (Standley et al., 2000; Scott et al., 2001, 2003; Carroll and Zukin, 2002). Further, distinct NR1 splice variants have been reported to interact with distinct proteins: the C0 cassette has been shown to bind calmodulin (Wyszynski et al., 1997; Zhang et al., 1998), $\alpha$-actinin (Wyszynski et al., 1997), and CaMKII $\alpha$ (Bayer and Schulman, 2001; Leonard et al., 2002); and the C1 cassette has been reported to bind neurofilament L (Ehlers et al., 1998) and yotiao (Lin et al., 1998). We do not know whether importin $\alpha$ binding to NR1 modulates membrane trafficking of the receptor, and/or whether it competes with or regulates the binding of other NR1-interacting proteins. It is probable, however, that the interaction of NR1 with its binding partners is highly regulated. The stimulus-induced release of importin $\alpha$ from NR1 likely allows other NR1-interacting proteins to bind. In this regard, it is appealing to speculate that the regulated importin $\alpha$-NR1 interaction provides a mechanism for tagging synapses during transcription-dependent plasticity (Frey and Morris, 1997), with stimulated, "tagged" synapses containing NR1 subunits that no longer bind importin $\alpha$.

Activity-dependent tethering of importin $\alpha$ at the synapse by regulated binding to NR1 provides an elegant mechanism for integrating synaptic events with nuclear signaling (for our model, see Fig. 6). We expect, however, that it represents only one of multiple synapse-to-nucleus signaling pathways. Thus, importin $\alpha$ isoforms may interact with additional receptors and thereby be responsive to a range of stimuli that elicit transcription, including neuromodulators such as dopamine and inhibitory inputs. Future studies aimed at detailed molecular dissection of the importin $\alpha-\mathrm{NR} 1$ interaction, at identification of the synaptically localized cargoes that importins carry to the nucleus, and at characterization of additional synapse-to-nucleus transport pathways promise to elucidate the cell biological mechanisms whereby synaptic stimulation leads to transcription-dependent, persistent changes in neuronal function.

\section{References}

Al-Hallaq RA, Conrads TP, Veenstra TD, Wenthold RJ (2007) NMDA diheteromeric receptor populations and associated proteins in rat hippocampus. J Neurosci 27:8334-8343.
Bayer KU, Schulman H (2001) Regulation of signal transduction by protein targeting: the case for CaMKII. Biochem Biophys Res Commun 289:917-923.

Bradley J, Carter SR, Rao VR, Wang J, Finkbeiner S (2006) Splice variants of the NR1 subunit differentially induce NMDA receptor-dependent gene expression. J Neurosci 26:1065-1076.

Carroll RC, Zukin RS (2002) NMDA-receptor trafficking and targeting: implications for synaptic transmission and plasticity. Trends Neurosci 25:571-577.

Cohen S, Greenberg ME (2008) Communication between the synapse and the nucleus in neuronal development, plasticity, and disease. Annu Rev Cell Dev Biol 24:183-209.

Cokol M, Nair R, Rost B (2000) Finding nuclear localization signals. EMBO Rep 1:411-415.

De Jongh KS, Colvin AA, Wang KK, Catterall WA (1994) Differential proteolysis of the full-length form of the L-type calcium channel alpha 1 subunit by calpain. J Neurochem 63:1558-1564.

Dieterich DC, Karpova A, Mikhaylova M, Zdobnova I, König I, Landwehr M, Kreutz M, Smalla KH, Richter K, Landgraf P, Reissner C, Boeckers TM, Zuschratter W, Spilker C, Seidenbecher CI, Garner CC, Gundelfinger ED, Kreutz MR (2008) Caldendrin-Jacob: a protein liaison that couples NMDA receptor signalling to the nucleus. PLoS Biol 6:e34.

Durand GM, Gregor P, Zheng X, Bennett MV, Uhl GR, Zukin RS (1992) Cloning of an apparent splice variant of the rat $N$-methyl-D-aspartate receptor NMDAR1 with altered sensitivity to polyamines and activators of protein kinase C. Proc Natl Acad Sci U S A 89:9359-9363.

Durand GM, Bennett MV, Zukin RS (1993) Splice variants of the N-methylD-aspartate receptor NR1 identify domains involved in regulation by polyamines and protein kinase C. Proc Natl Acad Sci USA 90:6731-6735.

Ehlers MD (2003) Activity level controls postsynaptic composition and signaling via the ubiquitin-proteasome system. Nat Neurosci 6:231-242.

Ehlers MD, Zhang S, Bernhadt JP, Huganir RL (1996) Inactivation of NMDA receptors by direct interaction of calmodulin with the NR1 subunit. Cell 84:745-755.

Ehlers MD, Fung ET, O’Brien RJ, Huganir RL (1998) Splice variant-specific interaction of the NMDA receptor subunit NR1 with neuronal intermediate filaments. J Neurosci 18:720-730.

Frey U, Morris RG (1997) Synaptic tagging and long-term potentiation. Nature 385:533-536.

Goldfarb DS, Corbett AH, Mason DA, Harreman MT, Adam SA (2004) Importin alpha: a multipurpose nuclear-transport receptor. Trends Cell Biol 14:505-514.

Gomez-Ospina N, Tsuruta F, Barreto-Chang O, Hu L, Dolmetsch R (2006) The $\mathrm{C}$ terminus of the L-type voltage-gated calcium channel $\mathrm{Ca}(\mathrm{V}) 1.2$ encodes a transcription factor. Cell 127:591-606.

Guillemain G, Muñoz-Alonso MJ, Cassany A, Loizeau M, Faussat AM, Burnol AF, Leturque A (2002) Karyopherin alpha2: a control step of glucose-sensitive gene expression in hepatic cells. Biochem J 364:201-209.

Hanz S, Perlson E, Willis D, Zheng JQ, Massarwa R, Huerta JJ, Koltzenburg M, Kohler M, van-Minnen J, Twiss JL, Fainzilber M (2003) Axoplasmic importins enable retrograde injury signaling in lesioned nerve. Neuron 40:1095-1104.

Ho OH, Delgado JY, O’Dell TJ (2004) Phosphorylation of proteins involved in activity-dependent forms of synaptic plasticity is altered in hippocampal slices maintained in vitro. J Neurochem 91:1344-1357.

Hollmann M, Boulter J, Maron C, Beasley L, Sullivan J, Pecht G, Heinemann S (1993) Zinc potentiates agonist-induced currents at certain splice variants of the NMDA receptor. Neuron 10:943-954.

Holmes KD, Mattar P, Marsh DR, Jordan V, Weaver LC, Dekaban GA (2002) The C-terminal C1 cassette of the $\mathrm{N}$-methyl-D-aspartate receptor 1 subunit contains a bi-partite nuclear localization sequence. J Neurochem 81:1152-1165.

Husi H, Grant SG (2001) Isolation of 2000-kDa complexes of N-methyl-Daspartate receptor and postsynaptic density 95 from mouse brain. J Neurochem 77:281-291.

Jordan BA, Kreutz MR (2009) Nucleocytoplasmic protein shuttling: the direct route in synapse-to-nucleus signaling. Trends Neurosci 32:392-401.

Lai KO, Zhao Y, Ch'ng TH, Martin KC (2008) Importin-mediated retrograde transport of CREB2 from distal processes to the nucleus in neurons. Proc Natl Acad Sci U S A 105:17175-17180.

Leonard AS, Bayer KU, Merrill MA, Lim IA, Shea MA, Schulman H, Hell JW 
(2002) Regulation of calcium/calmodulin-dependent protein kinase II docking to $N$-methyl-D-aspartate receptors by calcium/calmodulin and alpha-actinin. J Biol Chem 277:48441-48448.

Lin JW, Wyszynski M, Madhavan R, Sealock R, Kim JU, Sheng M (1998) Yotiao, a novel protein of neuromuscular junction and brain that interacts with specific splice variants of NMDA receptor subunit NR1. J Neurosci 18:2017-2027.

Malenka RC, Bear MF (2004) LTP and LTD: an embarrassment of riches. Neuron 44:5-21.

Marsh DR, Holmes KD, Dekaban GA, Weaver LC (2001) Distribution of an NMDA receptor:GFP fusion protein in sensory neurons is altered by a C-terminal construct. J Neurochem 77:23-33.

Monyer H, Burnashev N, Laurie DJ, Sakmann B, Seeburg PH (1994) Developmental and regional expression in the rat brain and functional properties of four NMDA receptors. Neuron 12:529-540.

Moriguchi S, Han F, Nakagawasai O, Tadano T, Fukunaga K (2006) Decreased calcium/calmodulin-dependent protein kinase II and protein kinase $\mathrm{C}$ activities mediate impairment of hippocampal long-term potentiation in the olfactory bulbectomized mice. J Neurochem 97:22-29.

Mu Y, Otsuka T, Horton AC, Scott DB, Ehlers MD (2003) Activitydependent mRNA splicing controls ER export and synaptic delivery of NMDA receptors. Neuron 40:581-594.

Nayak AS, Moore CI, Browning MD (1996) Ca2+/calmodulin-dependent protein kinase II phosphorylation of the presynaptic protein synapsin I is persistently increased during long-term potentiation. Proc Natl Acad Sci U S A 93:15451-15456.

Osten P, Valsamis L, Harris A, Sacktor TC (1996) Protein synthesisdependent formation of protein kinase $\mathrm{M} \zeta$ in long-term potentiation. J Neurosci 16:2444-2451.

Otis KO, Thompson KR, Martin KC (2006) Importin-mediated nuclear transport in neurons. Curr Opin Neurobiol 16:329-335.

Pérez-Otaño I, Ehlers MD (2005) Homeostatic plasticity and NMDA receptor trafficking. Trends Neurosci 28:229-238.

Perry RB, Fainzilber M (2009) Nuclear transport factors in neuronal function. Semin Cell Dev Biol 20:600-606.

Poon IK, Jans DA (2005) Regulation of nuclear transport: central role in development and transformation? Traffic 6:173-186.

Scott DB, Blanpied TA, Swanson GT, Zhang C, Ehlers MD (2001) An NMDA receptor ER retention signal regulated by phosphorylation and alternative splicing. J Neurosci 21:3063-3072.
Scott DB, Blanpied TA, Ehlers MD (2003) Coordinated PKA and PKC phosphorylation suppresses RXR-mediated ER retention and regulates the surface delivery of NMDA receptors. Neuropharmacology 45:755767.

Scott DB, Michailidis I, Mu Y, Logothetis D, Ehlers MD (2004) Endocytosis and degradative sorting of NMDA receptors by conserved membraneproximal signals. J Neurosci 24:7096-7109.

Sheng M, Cummings J, Roldan LA, Jan YN, Jan LY (1994) Changing subunit composition of heteromeric NMDA receptors during development of rat cortex. Nature 368:144-147.

Standley S, Roche KW, McCallum J, Sans N, Wenthold RJ (2000) PDZ domain suppression of an ER retention signal in NMDA receptor NR1 splice variants. Neuron 28:887-898.

Sugihara H, Moriyoshi K, Ishii T, Masu M, Nakanishi S (1992) Structures and properties of seven isoforms of the NMDA receptor generated by alternative splicing. Biochem Biophys Res Commun 185:826-832.

Thompson KR, Otis KO, Chen DY, Zhao Y, O’Dell TJ, Martin KC (2004) Synapse to nucleus signaling during long-term synaptic plasticity; a role for the classical active nuclear import pathway. Neuron 44:997-1009.

Tingley WG, Ehlers MD, Kameyama K, Doherty C, Ptak JB, Riley CT, Huganir RL (1997) Characterization of protein kinase A and protein kinase C phosphorylation of the $\mathrm{N}$-methyl-D-aspartate receptor NR1 subunit using phosphorylation site-specific antibodies. J Biol Chem 272:5157-5166.

Torgerson TR, Colosia AD, Donahue JP, Lin YZ, Hawiger J (1998) Regulation of NF-kappa B, AP-1, NFAT, and STAT1 nuclear import in T lymphocytes by noninvasive delivery of peptide carrying the nuclear localization sequence of NF-kappa B p50. J Immunol 161:6084-6092.

Wyszynski M, Lin J, Rao A, Nigh E, Beggs AH, Craig AM, Sheng M (1997) Competitive binding of alpha-actinin and calmodulin to the NMDA receptor. Nature 385:439-442.

Xia H, Hornby ZD, Malenka RC (2001) An ER retention signal explains differences in surface expression of NMDA and AMPA receptor subunits. Neuropharmacology 41:714-723.

Zhang S, Ehlers MD, Bernhardt JP, Su CT, Huganir RL (1998) Calmodulin mediates calcium-dependent inactivation of $N$-methyl-D-aspartate receptors. Neuron 21:443-453.

Zukin RS, Bennett MV (1995) Alternatively spliced isoforms of the NMDARI receptor subunit. Trends Neurosci 18:306-313. 